\title{
LOS PACTOS SOCIALES EN LA EXPERIENCIA ARGENTINA. SU INFLUENCIA EN EL DERECHO DEL TRABAJO Y POSIBLE TRASLACIÓN'
}

POR RICARDO FRANCISCO SECO ${ }^{2}$

Sumario: I.- Introducción. II.- Los diversos pactos sociales en la historia argentina. Caracteres epocales. 1.-Primer Pacto Social. 2.Segundo Pacto Social. 3.- El Acuerdo Marco de 1994. 4.-Otros intentos de Pactos. 5.-Valoración. Razones de los fracasos. 6.-Posible traslación. III.-Conclusión.

\section{I.- Introducción}

Uno de los temas del XXII Congreso Mundial de la Sociedad Internacional de Derecho del Trabajo y de la Seguridad Social, Turín 2018, es "El papel del Estado y las relaciones industriales".

En la República Argentina la intensa participación del Estado es un particularismo que caracteriza a las relaciones industriales y laborales, al Derecho del Trabajo argentino y, en especial, al "modelo sindical argentino". ${ }^{3}$

Un modo especial de esa intervención del Estado ha sido la promoción de pactos sociales. Examinaremos la influencia que los diversos Pactos Sociales argentinos han tenido en el Derecho del Trabajo argentino, las razones de dicha influencia, su éxito o fracaso y verificaremos si es posible que la experiencia nacional pueda trasladarse o no a otros países.

\section{II.- Los diversos pactos sociales en la historia argentina. Caracteres epocales 1.-Primer Pacto Social}

a)El primer intento de Pacto Social ocurrió el 21 de marzo de 1955, en la inauguración del Congreso Nacional de Productividad y Bienestar Social, durante el segundo gobierno del presidente Perón.

b) La clase trabajadora argentina ganó muchas posiciones durante el gobierno justicialista, que se sustentaba en el apoyo multitudinario de los trabajadores argentinos.

\footnotetext{
1 Ponencia no oficial presentada en el XXII Congreso Mundial de la Sociedad Internacional de Derecho del Trabajo y de la Seguridad Social, desarrollado en Turín, Italia, del 4 al 7 de setiembre de 2018.

2 Ricardo Francisco Seco, abogado y notario(Universidad Católica de Córdoba), doctor en Derecho y Ciencias Sociales(Universidad Nacional de Córdoba), profesor de DTySS de la UCC y de la UBP y de posgrado de diversas universidades argentinas y latinoamericanas, exvocal de la Cám.CC.y Trab., Cruz del Eje, Provincia de Córdoba, República Argentina, publicista.

3 SECO, Ricardo, "El modelo sindical y la negociación colectiva en Argentina. Características principales", en Revista de Derecho de la Universidad San Sebastián 23/2017, http://www.rduss.com, consultada el 30 de diciembre de 2017.

Ver también CORTE, Néstor, El modelo sindical argentino, Rubinzal-Culzoni, Santa Fe, 1994, p.14.
} 
El poder ganado por los obreros se manifestaba en la capacidad de control que las comisiones internas y cuerpos de delegados tenían sobre el manejo de las cuestiones de las empresas. Los avances jurídicos de los trabajadores afectaron derechos de los empresarios desde 1945 en adelante.

Un poco antes, mediante el decreto №32.347- del 30 de noviembre de 1944, elaborado por Perón y su equipo en la Secretaría de Trabajo y Previsión- se crearon y organizaron los Tribunales del Trabajo como fuero especializado de la Capital Federal. Luego ello se extendió a todo el país.

Un ejemplo paradigmático de esos variados avances fue el decreto 33.302/454. Éste extendió el preaviso e indemnización por despido a todos los trabajadores privados y estableció el pago del aguinaldo. Fue ratificado por la ley $12.921^{5}$ en el primer periodo constitucional de gobierno peronista.

c) Pero el mayor cambio fue la Constitución Nacional sancionada en 1949.Ella incorporó los derechos sociales al texto constitucional. Fue abrogada en 1956.

En Argentina se recibía "los ecos del debate que se venía dando desde fines del siglo $\mathrm{XIX}$, en torno al derecho social, que lentamente fue ganando posiciones en el mundo jurídico liberal de entonces, no sin grandes resistencias. En efecto, el así llamado 'nuevo derecho' ponía en cuestión algunos principios sagrados de la filosofía liberal, como la noción del contrato libremente consentido por las partes, el individualismo o la igualdad y proponía a cambio la idea de la justicia social, de la esencial desigualdad de fuerzas y oportunidades entre capital y trabajo, y por lo tanto de la relación que se establece entre patronos y trabajadores. En tal sentido, lo que estaba siendo puesto en cuestión crecientemente era la suficiencia del derecho civil -de los códigos civiles y, luego, de la justicia civil- para dar cuenta de la nueva cuestión social que había planteado la revolución industrial en Europa y ya era evidente en América Latina desde fines de siglo XIX." d) No pudo prosperar ese primer ensayo de pacto social porque, además de problemas propios de la época, el gobierno constitucional fue derrocado en setiembre de 1955.

\section{2.- Segundo Pacto Social}

a) Un primer antecedente fue el Programa de Reconstrucción y Liberación Nacional presentado en mayo de 1973 por el partido vencedor de las elecciones del 11 de marzo de 1973, cuando se salía de la dictadura cívico-militar que asumió en 1966,la que entregó el poder el 25 de mayo de 1973.

b)El 8 de junio de 1973 se firmó el "Acta de Compromiso Nacional para la Reconstrucción, la Liberación Nacional y la Justicia Social”, más conocida como Pacto Social.

Fue una medida económica y política que cruzó la orientación del gobierno peronista surgido el 11 de marzo de 1973 hasta junio del 75.?

Abarcó las primeras fases del gobierno de Héctor Cámpora, la escueta tercera presidencia de Juan Domingo Perón y algo de la de su sucesora María Estela Martínez de Perón. Suscribieron el pacto el sindicalismo nucleado en la Confederación General del Trabajo, presidida por José Ignacio Rucci, y el empresariado argentino nucleado a su vez en la Confederación General Económica, presidida por Julio Broner. El Ministro de Economía era José Ber Gelbard, que fue fundador y presidente de la Confederación General Económica.

4 B.O.31/12/1945.

5 B.O.27/6/1947.

6 PALACIO, Juan Manuel, "El peronismo y la invención de la justicia del trabajo en la Argentina en http://journals.openedition.org/nuevomundo/65765, consultada el 16 de enero de 2018 .

7 Ver https://www.laizquierdadiario.com/Que-fue-el-pacto-social, consultado el 8 de febrero de 2018. 
En el contenido del pacto aparecía como objetivo concertar la política económica nacional entre los tres sectores claves de la Economía: el gobierno, la industria y los sindicatos en pos de conseguir la recuperación económica del país que tenía problemas no sólo coyunturales como la inflación, sino también estructurales. Se acordaron precios y salarios, se congelaron las paritarias por dos años, se fijó un salario mínimo -muy por debajo del exigido por las organizaciones de base peronistas y de izquierda- y se fijó el aumento de los servicios básicos. Aunque Gelbard decía que se buscaba lograr "inflación cero", el gobierno peronista quería encauzar los reclamos de los trabajadores por vías institucionales y mantenerlos desmovilizados (bajo la disciplina de la CGT), a la vez que fortalecía a la cúpula sindical reconociéndola como única representante de los trabajadores."”

Eran objetivos del Pacto: "1) Alcanzar la participación de los asalariados en el 40-50\% del ingreso nacional, en un lapso de 4 años (es decir, para 1977-1978); incrementando los salarios reales de la masa obrera argentina. 2) Mitigar la pesada inflación que era siempre un problema recurrente de la Argentina (lo que indicaba lo sensible del asunto, evitar la espiral de inflación de costos).3) Todo esto era con el fin de consolidar el crecimiento económico."

En él se propiciaba: "Congelamiento de los precios (para detener el principio de hiperinflación que amenazaba al país). Alza general de sueldos ( $\$ 200$ mensuales), para que los conflictos laborales cesen. Suspensión de la negociación colectiva sobre el salario durante 2 años."

c) Este Pacto tuvo una primera fase desde junio de 1973 a julio de 1974. Debutó poco después de que Héctor José Cámpora estuviera en la presidencia por un efímero lapso.

Sus primeros resultados fueron absolutamente positivos: "En primer lugar tenía una coyuntura internacional favorable (altos precios de las exportaciones tradicionales, y una cosecha récord con exportaciones en aumento). La alta inflación que amenazaba continuamente a la Argentina, menguó (del $62 \%$ al $17 \%$ anual) y se intentaba llegar a una "inflación O". Los salarios reales se recuperaron en un 13,33\%. Se revirtió la complicada situación de la balanza de pagos gracias a la acumulación de superávit por el comercio exterior. El incremento de los salarios y la expansión del gasto público alentaban a la actividad interna." 10

La crisis que sobrevino a fines de 1973 obligó a que el déficit se agravara frente a la nueva merma de divisas por la baja de las exportaciones tradicionales. El Estado también estaba sosteniendo a la masa empresaria dentro del pacto mediante el otorgamiento de cuantiosos subsidios que favorecían al empresariado nacional.

Por otro lado el peronismo gobernante estaba sumamente dividido en sectores de izquierda y derecha. La movilización de bases era desbordante: tomas fabriles, pedido de recomposiciones salariales, planteos a gerentes y patrones resquebrajaban de a poco las cláusulas del pacto social.

El propio Perón trató de encargarse de fortalecer al sindicalismo peronista tradicional y de así debilitar a la izquierda peronista y marxista.

En diciembre de 1973 el Pacto entró en una fase complicada; "comenzaron a acumularse los problemas. Perón, a pesar de su carisma y conocimientos sobre política y economía, no era el mismo de antes. Lo que sucedió fue lo que en general sucede con la expansión de la actividad: el consumo crece, y reaparece la inflación.”’11

8 Îdem nota anterior.

9 Ibidem.

10 Ibidem.

11 ROMERO, Luis Alberto, Breve Historia Contemporánea de la Argentina, Fondo de Cultura Económica de Argentina, 2001, citado en https://www. laizquierdadiario.com/Que-fue-el-pacto-social, consultado el 8 de febrero de 2018. 
A nivel internacional se había producido la crisis del petróleo ${ }^{12}$ justo cuando la industria estaba en plena reactivación y ocurrió una modificación objetiva de las condiciones de trabajo de las personas. Las importaciones se encarecieron complicando la balanza comercial nuevamente, y como estocada final el Mercado Común Europeo dejó de importar la carne argentina.

Los empresarios comenzaron a sistemáticamente violar el pacto ante el comienzo de la crisis. 'Los precios, que 'necesitaban' aumentar por los aumentos en el costo de los insumos, no se ajustaban a los controles que estaban legalmente constituidos. El gobierno aprobó un subsidio cambiario, previendo el disgusto de la CGT, y también fijó un especial para las importaciones (revaluación del peso)."

Ante estas dificultades el plan debió ser reformulado, y la renegociación se produjo en marzo de 1974. "Este nuevo diálogo consumó nuevos aumentos que terminaron dejando insatisfechos a los trabajadores, el virtual rompimiento que ya sufría el pacto llevó al mismo Perón a pedir la cooperación de los actores y amenazar con su renuncia, en el que fuera su último discurso en público."’13

Se vivió el desabastecimiento y el mercado negro a donde el control de precios no llegaba. Las bases obreras ya que no acataban el pacto lo que echó por tierra la posibilidad de un triunfo del acuerdo.

d) Una segunda fase del Pacto se dio desde julio de 1974. Ante la desaparición del viejo líder no era posible frenar y contener los desbordes.

La nueva presidente María Estela Martínez no demostró capacidad para manejar semejante desborde económico y social entre crisis interna y externa, entre ultraderecha e izquierda combativa devenida en algunos sectores en guerrillas violentas. En el inconsciente colectivo está que quien realmente gobernaba el país durante su presidencia era su Ministro de Bienestar Social (José López Rega). Comenzó una purga de elementos indeseables en el gabinete nacional, en el Congreso y sobre todo en las universidades, donde el ala de izquierda del peronismo tenía amplios lugares. En ese escenario conflictivo y traumático las organizaciones de izquierda rompieron con el débil gobierno peronista.

e) Si bien no puede decirse estrictamente que fue consecuencia del Pacto Social, recordemos que el gobierno constitucional de 1973 encargó la redacción de un anteproyecto de Ley de Contrato de Trabajo ley al abogado correntino, radicado en Mar del Plata, Norberto Oscar Centeno.

El Poder Ejecutivo nacional introdujo algunas modificaciones en su texto y lo remitió al Poder Legislativo. Ambas Cámaras, a su vez, le introdujeron modificaciones.

Finalmente se sancionó el 11 de setiembre de 1974 la ley 20.744, que aprobó el Régimen de Contrato de Trabajo (publicada en el B.O. 27/9/74). ${ }^{14}$

f) La ronda de negociaciones colectivas de 1974/1975 resultó muy positiva consolidándose el sistema de negociación colectiva. ${ }^{15}$

g) El 4 de junio de 1975, el entonces Ministro de Economía Celestino Rodrigo dispuso "un brutal ajuste que duplicó los precios y provocó una crisis en el gobierno de Isabel Perón. Rodrigo quería eliminar la distorsión de los precios relativos."16

El "Rodrigazo" (así llamado en alusión al ministro Rodrigo) "fue el primer mega-ajuste de la historia económica argentina, y que inició la serie de planes que siempre incluían la

\footnotetext{
12 Ver http://economipedia.com/definiciones/crisis-del-petroleo-1973.html, consultada el 31 de marzo de 2018. 13 ROMERO, ob.cit.

14 Ver en http://www.mecon.gov.ar.

15 ARESE, César, "El proceso de reformas laborales",en Revista de Derecho Laboral-Actualidad, 2017-2, Rubinzal Culzoni, Santa Fe, 2017, p.217.

16 Ver https://www.sitiosargentina.com.ar/notas/2012/junio/rodrigazo.htm consultado el 8 de febrero de 2018.
} 
fórmula "devaluación y tarifazo" para corregir distorsiones de la economía." Implicó una devaluación de $160 \%$ para el cambio comercial y 100\% para el cambio financiero, un aumento de los combustibles de un $180 \%$ y de todas las tarifas públicas en hasta $100 \%$. Las deudas en pesos, naturalmente tuvieron una enorme licuación. Los salarios se ajustaron a $45 \%$, lo cual era, de hecho, una brusca disminución del poder adquisitivo. La presión sindical llevó que luego hubiera nuevos ajustes, que de todas formas quedaron licuados porque la inflación se disparó por encima de un 180 por ciento anual."”17

La tasa de inflación llegó hasta tres dígitos anuales y los precios nominales subieron en $183 \%$ al finalizar 1975. Se produjo desabastecimiento de gran cantidad de productos de necesidad primaria (alimentos), combustibles y otros insumos para transportes. En ese marco, los gremios consiguieron aumentos del 100\%, pero el Ministerio de Trabajo amenazó con no homologarlos.

El 27 de junio de 1975 la CGT lanzó un paro por 48 horas y una manifestación que enfrentó por primera vez en la historia a un gobierno peronista reclamando la renuncia de López Rega y de Rodrigo.

El primero finalmente renunció y se exilió en Suiza el 19 de julio. El 21 cayó Rodrigo y su plan económico pasaba a la historia.

h) El Pacto Social, impulsado por el entonces ministro Ber Gelbard, bajó la inflación a la mitad, pero en forma tan voluntarista que generó las condiciones para el estallido del "Rodrigazo" en 1975. ${ }^{18}$

En 1974 estaban finalizando los llamados "Treinta años gloriosos" que se extendieron desde el fin de la Segunda Gran Guerra en adelante. ${ }^{19}$

En el mundo, sumergido en la crisis petrolera de 1973-1975, comenzaba la posterior debacle del "Estado de Bienestar" que se montó principalmente en Europa luego de aquella guerra y se exportó como modelo. Además empezaba una época de cambios, nunca vistos en su profundidad y en su extensión, los que llegarían hasta nuestros días, ya entrado el tercer milenio.

Con ello terminó el Pacto Social. El país se desangraba con el terrorismo de las organizaciones guerrilleras y el comienzo del terrorismo de Estado, preludio del golpe de Estado cívico-militar del 24 de marzo de 1976 que terminó con el gobierno peronista y comenzó la larga noche del autodenominado Proceso de Reorganización Nacional.

i) Una de las primeras víctimas del gobierno de facto fue la Ley de Contrato de Trabajo, modificada el 21 de abril de 1976 por la regla estatal $21.297 .{ }^{20}$ Ella reformó la ley 20.744 derogando veinticinco de sus artículos, modificando otros noventa y siete y agregando un artículo a su texto. ${ }^{21}$

A su vez el decreto $390 / 76^{22}$ ordenó el texto de la LCT.

\section{3.- El Acuerdo Marco de 1994}

a) El "Acuerdo Marco para el Empleo la Productividad y la Equidad Social" fue suscripto el 25 de julio de 1994 entre el Gobierno Nacional bajo la presidencia de Carlos Menem, la

17 Ver http://www.iprofesional.com/notas/152878-Que-fue-el-Rodrigazo-del-que-hablo-Mendiguren-y-al-que-le-temen-empresarios-argentinos?page_ y=1530; CORNAGLIA, Ricardo J., La reforma de la Ley de Contrato de Trabajo al cumplirse treinta años de su sanción en http://rjcornaglia.blogspot.com. ar/2014/08/la-reforma-de-la-ley-de-contrato-de_1.html.

18 Ver ¿Pacto social?: mejor un acuerdo por la competitividad en http://www.ieral.org/noticias/pacto-social-mejor-acuerdo-competitividad-1730. html,consultada el 8 de febrero de 2018.

19 VÁZQUEZ VIALARD, Antonio, “Ayer, hoy y mañana en el derecho del trabajo", en Relaciones Laborales y Seguridad Social, Año I, № 1, marzo de 1995, Interoceánica, Buenos Aires, 1995, p.49..

20 B.O. $29 / 4 / 1976$

21 B.O.21/1/1976

22 B.O.15/5/1976.

AÑO 1 • NÚMERO 1 
Confederación General del Trabajo y todas las Cámaras empresarias, en plena época de vigencia de la ideología neoliberal en el mundo. ${ }^{23}$

Era Ministro de Trabajo el Dr. Armando Caro Figueroa. Se consensuó todo el programa de flexibilidad y desprotección laboral que se aplicó antes en España. ${ }^{24}$

Las principales cláusulas consensuadas fueron: la instauración de contratos a plazo sin requisitos de objetividad (contratos basura); el periodo de prueba; la nueva Ley de Riesgos del Trabajo; la conciliación laboral obligatoria; los contratos a tiempo parcial, el estatuto para Pymes; los contratos de aprendizaje; nuevas formas de segmentación de la actividad empresaria que deben quedar excluidas del art.30 de la LCT; la reforma a la ley de quiebras; entre otras propuestas.

b) Estas iniciativas, en forma muy acelerada, fueron convertidas en proyectos de ley y votadas en el Congreso Nacional.

La ley $24.465^{25}$ "introdujo el periodo de prueba, el contrato de aprendizaje, el contrato a tiempo parcial y el contrato (promovido) especial de fomento del empleo". ${ }^{26}$

Más tarde la ley $24.467^{27}$,régimen de las PYMES, flexibilizó el régimen del preaviso y otorgó "por medio de la disponibilidad colectiva la posibilidad del fraccionamiento del SAC y el momento de goce de las vacaciones." ${ }^{28}$

La ley $25.013^{29}$ modificó el régimen de despidos rebajando las indemnizaciones por antigüedad o despido, omisión del preaviso y fuerza mayor y falta o disminución de trabajo, y con ello los costos empresarios; también "derogó las contrataciones promovidas que había introducido la ley 24.013 y el contrato especial de la ley 24.465"; además redujo "las indemnizaciones de los trabajadores con una antigüedad menor a los dos años (eliminación del mínimo de dos meses) lo que- sumado al periodo de prueba de 30 días sin cargas sociales [luego elevado a tres meses por la ley 25.250]- afectó el derecho a la estabilidad y permanencia en el empleo." ${ }^{30}$ La incorporación de mano de obra a través de organizaciones de servicios eventuales por la ley 25.013 implicó también un alto grado de flexibilización.

Allí se enmarca la reducción de los llamados costos no salariales, como sucedió antes con la ley $24.241^{31}$ que, en general, privatizó el régimen de jubilaciones y pensiones (las AFJP). La ley $24.557^{32}$ privatizó la cobertura de los accidentes y enfermedades del trabajo, con un diseño de seguro obligatorio y hermético ${ }^{33}$ (Ley de Riesgos del Trabajo) y la ley $24.714^{34}$ modificó el régimen de asignaciones familiares restringiéndolas en general.

La flexibilidad en la gestión de la crisis se hizo antes con el procedimiento preventivo

\footnotetext{
23 SECO, Ricardo Francisco, "Breves aproximaciones al neoliberalismo y su influencia en el Derecho del Trabajo argentino", en Libro de Ponencias IX Jornadas sobre Derecho del Trabajo y de la Seguridad Social, Cruz del Eje, Provincia de Córdoba, 10 y 11 de octubre de 2003, Alveroni, Córdoba, 2003,ps.179 a 190.

24 SCHICK, Horacio, Informe Laboral N 56 Sobre el Acuerdo Marco del 25 de Julio de 1994 en http://www.estudioschick.com.ar/in_56.pdf,consultada el 8 de febrero de 2018 .

25 B.O.28/3/1995

26 GRISOLÍA, Julio Armando, "Las consecuencias de las principales reformas al derecho individual del trabajo en el periodo 1991-2001", en Libro de Ponencias VIII Jornadas sobre Derecho del Trabajo y de la Seguridad Social, Cruz del Eje, 7 y 8 de setiembre de 2001,Alveroni, Córdoba, p.127

27 B.O.28/3/1995.

28 GRISOLÍA, ob.cit.

29 B.O.24/9/1998.

30 GRISOLÍA, ob.cit.

31 B.O.18/10/1993.

32 B.O.4/10/1995.

33 BILLOUROU DE COMADIRA, Solange, “La reforma laboral: ¿Profundización o revisión de 'tendencias flexibilizadoras’?”, TySS-1999,151.

34 B.O. $18 / 10 / 1996$
} 
reglado por la ley $24.013^{35}$ y la ley $24.522^{36}$ de Concursos y Quiebras que innovó respecto a las propias fuentes de regulación del contrato de trabajo con la caducidad de los convenios colectivos en concursos y quiebras. ${ }^{37}$

c) Las experiencias nacionales antes citadas $^{38}$ no sirvieron "per se" para generar nuevos puestos de trabajo ni reducir el desempleo. ${ }^{39}$

d) Sin embargo la lucha judicial de los abogados, la evolución jurídica y constitucional y, en especial, la jurisprudencia de la Corte Suprema desde 2004 a 2013, pusieron un límite parcial a estos retrocesos. ${ }^{40}$

Un ejemplo de ellos es que, de los cincuenta y un artículos de la LRT, han sido declarados inconstitucionales al menos once, algunos de manera expresa y otros por implicancia o de manera tácita. Los artículos impugnados tienen entidad tal en el sistema que éste ha quedado completamente "desmantelado".

e) En medio de la época neoliberal se dio la reforma constitucional de 1994. Con la constitucionalización de tratados internacionales y declaraciones sobre derechos humanos, art.75 inc. $22 \mathrm{CN}$, se impuso un marco al proceso flexibilizador porque ellos significan "un mínimo de derechos sociales", cuales "límites infranqueables para el legislador ordinario". ${ }^{41}$ La reforma de 199442, estableció el "derecho al desarrollo humano" en el art.75 inc.19, en relación con los arts.41 y 125 . El nuevo inciso ingresa derechamente a materia económica cuando se refiere "al progreso económico con justicia social, a la productividad de la economía nacional, a la generación de empleo, a la formación profesional de los trabajadores...". ${ }^{43}$

A su vez el art.75 inc.23, CN, establece "el principio de igualación sustancial" que ya estaba implícito en el art.14 bis, siendo destinatarios de esa norma, entre otros, los trabajadores...". El programa social incumplido del art.14 bis de la CN ha sido consolidado y profundizado con la reforma de $1994^{44}$, aún cuando el ambiente en que se vivía en ese tiempo histórico desde la ideología, la política y la economía, estaba imbuido de Neoliberalismo y no se caracterizaba por la vigencia y actualidad de semejantes ideas- fuerzas que quedaron plasmadas en el texto constitucional el que contradice esa postura jurídico- constitucional. ${ }^{45}$ Oscar Ermida Uriarte (de feliz memoria) los llamaba "contraataques protectores" pues se produjo la "incorporación, aún en las más altas jerarquías normativas, de normas, mandatos y principios propios de la teoría clásica del derecho laboral." ${ }^{46}$

\footnotetext{
35 B.O.5/12/1991.

36 B.O. $9 / 8 / 1995$.

37 BILLOUROU DE COMADIRA, ob.cit.; ARESE,ob.cit.

38 Hay otras más relacionadas con la reducción de sobrecostos derivados de la litigiosidad o a la descentralización de la negociación colectiva que son profundamente indicados por BILLOUROU DE COMADIRA, ob.cit., a la que cabe remitirse.

39 GHERSI, Carlos A., La reforma laboral. Ley 25.013. Política económica. Flexibilización y empresa. Rol del Estado. Doctrina y jurisprudencia, Ed. Universidad, Buenos Aires,1999,p.89.

40 ARESE, ob.cit.

41 BIDART CAMPOS. Germán J., "El constitucionalismo social (Esbozo del modo socioeconómico de la constitución reformada en 1994)”, en Economía, Constitución y Derechos Sociales, BIDART CAMPOS, coordinador, EDIAR, Buenos Aires, 1997, p.175.

42 SABSAY, Daniel A.- ONAINDIA, José M., La Constitución de los argentinos, 2a ed. ampliada y actualizada, Errepar, Buenos Aires, 1995 , p.64.

43 GIANIBELLI, Guillermo - ZAS, Oscar, "Estado social en Argentina: modelo constitucional y divergencias infraconstitucionales", en CONTEXTOS, Revista Crítica de Derecho Social 1, Editores del Puerto, Buenos Aires, 1997, p.159.

44 Ídem nota anterior.

45 BIDART CAMPOS, Germán J, “La constitución económica (un esbozo desde el derecho constitucional argentino)“, LexisNexis Jurisprudencia Argentina, 5 de julio de 2002,JA 2002-II, fascículo n.10,p.2.

46 FUENTES PUELMA, Carlos, "La flexibilidad normativa laboral y su relación con la pequeña y mediana empresa latinoamericana", rev. Relaciones Laborales y Seguridad Social, Año I, No 8, enero de 1996, p.1129, citando a URIARTE, Oscar Ermida, en AA. VV. Experiencias de flexibilidad normativa, Universidad Nacional Andrés Bello, Chile, 1992, p.29 a 54.
} 
El edificio de la legislación de inspiración neoliberal instalado en los ochenta y noventa del siglo pasado fue desmontándose progresivamente por medio de leyes y sentencias judiciales y, con ello, la flexibilidad normativa se apaciguó grandemente. Pero no ha sucedido lo mismo con la flexibilidad fáctica. ${ }^{47}$

\section{4.-Otros intentos de Pactos}

a) A lo largo de la historia argentina hubo otros intentos de Pactos aunque menos notables que los mencionados, como fueron el Consejo Económico Social de 1946, o el Gran Acuerdo Nacional del presidente de facto Lanusse de 1971-1972.

Casi 30 años después el gobierno de Fernando de la Rúa encomendó al exministro de Trabajo, Alberto Flamarique, impulsar un Pacto con la CGT. Pero Armando Cavalieri, representante de los empleados de comercio, pronosticó el fracaso del plan y dijo: "Estamos ante un Gobierno que se llenó de economistas y, por lo tanto, ya sabemos hacia dónde camina: hacia el ajuste de la clase media y el mundo del trabajo". ${ }^{48}$

Otro intento más se hizo a fines de 2004. Los empresarios comenzaron a pergeñarlo con la CGT, hasta que el ministro de Economía, Roberto Lavagna tomó conocimiento de la iniciativa y la frenó con una explicación sencilla: "genera inflación"49.

b) La presidente Cristina Fernández de Kirchner habló en la campaña electoral de 2011 de Acuerdo, Pacto o Diálogo social ${ }^{50}$ pero poco concretó.

c) Mediante el decreto 1092/2016 del 12/10/2016 ${ }^{51}$ el presidente Macri convocó al Diálogo para la producción y el trabajo a los representantes de trabajadores y empresarios organizados en entidades representativas que los nuclean y a otros representantes de la sociedad civil que oportunamente determine la Jefatura de Gabinete de Ministros, con la finalidad de crear un espacio donde se discutan los lineamientos generales orientados a la creación de empleo, la protección del valor adquisitivo del salario y el crecimiento de la producción. Ordenó que funcionarios de diversas áreas trabajaran en comisiones referidas al sostenimiento y la promoción del empleo y al crecimiento de la producción. Se estableció que la primera reunión de las partes convocadas tendría lugar dentro de los treinta días a partir de la publicación del decreto, la cual sería convocada por la Jefatura de Gabinete de Ministros.

Producida la reunión se acordó un bono salarial para ser negociado por cada sector y un pacto antidespidos. Esa instancia naufragó rápidamente luego de algunas reuniones ampliamente publicitadas. ${ }^{52}$

\section{5.-Valoración. Razones de los fracasos}

a) No se registran normas laborales sancionadas como consecuencia directa de los dos primeros Pactos Sociales que se dieron en la historia argentina. Ellos fueron programas económico-sociales entre Estado, sindicatos y cámaras empresariales.

Ambos fracasaron, entre otras, por las razones políticas precitadas, a las que se añaden otras económicas locales y, además, el contexto internacional desfavorable (en el caso del segundo, la crisis petrolera de 1973-1975).

\footnotetext{
47 SECO, Ricardo Francisco, "La flexibilidad laboral. Sus luces y sus sombras. ¿¿n concepto antiguo que puede volver?”, Práctica Integral Córdoba, No 111 , mayo de 2016, Errepar, Buenos Aires, ps.57/68.

48 Ver http://economiaparatodos.net/el-pacto-social-imprescindible/ consultada el 8 de febrero de 2018.

49 Ídem nota anterior.

50 Ver https://www.cronista.com/impresageneral/La-tercera-version-del-Pacto-Social-en-la-Argentina-20051025-0056.htmlLa tercera versión del Pacto Social en la Argentina, consultado el 8 de febrero de 2018.

51 B.O.13/10/2016

52 ARESE, ob.cit.,p.221.
} 
b) El Acuerdo Marco de 1994 tuvo expresión directa en normas legales sancionadas por el Parlamento en consecuencia de aquél, teñidas de la ideología neoliberal reinante en ese momento ${ }^{53}$, que contaron con el apoyo de legisladores de origen sindical, que fueron claramente regresivas y perjudiciales a los derechos de los trabajadores.

c) Hizo falta más de una década para que esos retrocesos en general fueran superados por nuevas normas legales dictadas por el Parlamento o por criterios jurisprudenciales, en especial de la Corte Suprema de Justicia, pero aún así no se volvió a los niveles anteriores de protección. ${ }^{54}$

Así se compartió el nuevo paradigma del derecho internacional de los derechos humanos, que ilumina y contradice esos retrocesos dados en la época neoliberal, basados en la reforma de la Constitución Nacional de 1994.

d) La influencia ideológica neoliberal- que como toda ideología no se piensa sino que se respira- embargó a los representantes de los trabajadores de ese entonces que consintieron en general esos retrocesos.

El capitalismo criollo es profundamente cerrado, paternalista, despreciativo de la creatividad de los trabajadores y antepone al pleno desarrollo humano de las personas miembros de la empresa su propia lógica de producción y acumulación egoísta y materialista.

Tales aspectos aunque arraigados pueden ser revertidos porque no se fundan en la naturaleza de las cosas sino más bien en una cultura, nuestra cultura, la que tiene valores y desvalores.

f) Argentina padece lo que caracterizara Carlos Nino, de "anomia boba". ${ }^{5}$

Describe Nino "un escenario caótico en cierto modo, en el que las leyes, incluida la Constitución, se tergiversan o se desconocen, las normas se proclaman pero no se cumplen o sólo en parte, los deberes sociales, como la obligación de pagar impuestos, se evaden y las sanciones así como toda transacción entre particulares y el Estado, se 'arreglan' mediante sobornos."

Define a la anomia boba: "Una acción colectiva es anómica, en el sentido de ilegalidad "boba" que aquí nos interesa, si ella es menos eficiente que cualquier otra que se podría dar en la misma situación colectiva y en la que se observara una cierta norma. [...] Hay anomia boba sólo cuando la acción colectiva en cuestión se caracteriza por la inobservancia de normas y hay al menos una cierta norma que conduciría a una acción colectiva más eficiente en la misma situación a partir de las interacciones de individuos interesados exclusivamente en su propio beneficio ellos tienen la más alta probabilidad de quedar entrampados en las peores situaciones posibles para sus propios intereses, precisamente por la carencia de motivos altruistas que los induzcan a colaborar entre sí. De allí surge la clave para una posible superación de la anomia: ésta está dada por la vigencia de las normas morales propias de una ética universalista, que motiva a los agentes a actuar por pura convicción siguiendo la norma, es decir, sin cálculos de beneficios y perjuicio tenien-

\footnotetext{
53 SECO, Breves aproximaciones al neoliberalismo y su influencia en el Derecho del Trabajo argentino,cit.

54 SECO, La flexibilidad laboral. Sus luces y sus sombras, cit.

55 NINO, Carlos, Un país al margen de la ley, Ariel, Buenos Aires, 2011,ps.39 y 188-193.

Es aplicable a Argentina- por compartir la misma raíz histórica- lo que en Perú advirtió Ricardo Palma. "En tiempo de la Colonia, el Virrey tenía su manera de incumplir las normas y era ésta: "Después de dar cuenta de la cédula en el Real Acuerdo, poníase sobre sus puntales, cogía el papel o pegamento que la contenía, lo besaba si en antojo le venía, y luego, elevándolo a la altura de la cabeza, decía con voz robusta: Acato y no cumplo." Se comenta que: "Esto que cuenta Palma es vital, no sólo en materia económica sino también política, particularmente en un país donde desde la Colonia, como él dice, fue corriente el dicho: "la ley se acata pero no se cumple" de lo que se derivan varias observaciones: 1) Hay ley pero no institucionalidad y 2) No hay institucionalidad porque la ley es inaplicable", en Nota de VRedondoF : para explicar el significado tomo un párrafo de don Dr.Carlos Torres y Torres-Lara en el escrito "Retos de la consolidación democrática del Perú y la institucionalización", http://frasesportemas.blogspot.com/2010/09/acato-y-no-cumplo.html.

Se dice que "Obedezco, pero no cumplo,es una frase que en 1528, tiempos de Carlos V, ya se usaba en la América Española, para describir la actitud de algunos funcionarios coloniales locales hacia el Estado de la Corona, siendo el primero más conocido el incidente de Hernán Cortes con el entonces gobernador de Cuba, Diego Velázquez",en El baúl de José Alberto Cepas, en https://sites.google.com/site/joseacepas/articulos/obedezco-pero-nocumplo,ambas consultadas el 31 de marzo de 2018.
} 
do siempre en vista su aplicación imparcial para todos los afectados. Sin una vigencia efectiva de la norma moral resulta imposible pensar siquiera un escape de la situación de anomia en que se encuentran los agentes, ya que la obediencia a todas las demás normas jurídicas, sociales, etc., presupone la disposición moral a cumplir con ellas."

g) La cultura de los argentinos es muy especial; no tiene parangón en el mundo.

\section{6.-Posible traslación}

Transponer la experiencia argentina a otros países entendemos que es sumamente difícil. Sí es posible atender a las circunstancias políticas, económicas, sociales y culturales que llevaron que los ensayos de pactos sociales aludidos no hayan funcionado en este especial país, para evitarlos.

Se trata de sortear los escollos que aquí se plantearon y que llevaron a consagrar normas provenientes de ese Acuerdo Marco a las que juzgamos regresivas o in pejus para los derechos de los trabajadores.

El actual bloque de constitucionalidad federal, conformado por la Constitución Nacional y tratados sobre derechos humanos incorporados con nivel constitucional en 1994, donde se consagra el principio de progresividad ${ }^{56}$, impide el dictado de normas provenientes de acuerdos intersectoriales que perjudiquen los derechos de los trabajadores.

Argentina está obligada por la Declaración de la OIT sobre la justicia social para una globalización equitativa de 2008, que "expresa la visión contemporánea del mandato de la OIT en la era de la globalización. Uno de sus objetivos estratégicos para la concreción del Programa de Trabajo Decente es la promoción del diálogo social."

Éste funciona como la estrella polar que guía a los navegantes, al que no hemos renunciado pero tampoco alcanzado aún.

\section{III.-Conclusión}

1.- No se registran normas laborales sancionadas como consecuencia directa de los dos primeros Pactos Sociales que se dieron en la historia argentina.

Ambos fracasaron, entre otras, por las razones políticas precitadas, a las que se añaden otras económicas locales y, además, el contexto internacional desfavorable (en el caso del segundo la crisis petrolera de 1973-1975).

2.- El Acuerdo Marco de 1994 tuvo expresión directa en normas legales sancionadas por el Parlamento en consecuencia de aquél, que fueron claramente regresivas y perjudiciales a los derechos de los trabajadores.

Hizo falta más de una década para que esos retrocesos en general fueran superados por nuevas normas legales dictadas por el Parlamento o por criterios jurisprudenciales, en especial de la Corte Suprema de Justicia, pero aún así no se volvió a los niveles anteriores de protección.

3.- La influencia ideológica neoliberal- a los representantes de los trabajadores de ese entonces que consintieron en general esos retrocesos.

El capitalismo criollo es profundamente cerrado, paternalista, despreciativo de la creatividad de los trabajadores y antepone al pleno desarrollo humano de las personas miembros de la empresa su propia lógica de producción y acumulación egoísta y materialista.

\footnotetext{
56 CSJN, 11/8/2004, "Recurso de hecho deducido por la demandada en la causa Aquino, Isacio c/ Cargo Servicios Industriales S.A.":"Un principio arquitectónico del Derecho Internacional de los Derechos Humanos en general, y del PIDESC en particular es el de progresividad, "según el cual, todo Estado Parte se "compromete a adoptar medidas [...] para lograr progresivamente [...] la plena efectividad de los derechos aquí reconocidos" (art. 2.1)..."Existe una "fuerte presunción" contraria a que dichas medidas regresivas sean compatibles con el tratado (Comité de Derechos Económicos, Sociales y Culturales, Observación General N 14 y Nº 15, cits., págs. 103 - párr. 32- y 122 - párr. 19-, respectivamente), sobre todo cuando la orientación del PIDESC no es otra que "la mejora continua de las condiciones de existencia", según reza, preceptivamente, su art. 11.1. "El mentado principio de progresividad, que también enuncia la Convención Americana sobre Derechos Humanos precisamente respecto de los derechos económicos y sociales (art. 26).
} 
Tales aspectos aunque arraigados pueden ser revertidos porque no se fundan en la naturaleza de las cosas sino más bien en una cultura.

4.- Argentina padece lo que caracterizara Carlos Nino, de "anomia boba", sólo superable a partir de normas morales propias de una ética universalista, que motive a los agentes a actuar por pura convicción siguiendo la norma, es decir, sin cálculos de beneficios y perjuicio teniendo siempre en vista su aplicación imparcial para todos los afectados.

5.- Transponer la experiencia argentina a otros países es sumamente difícil.

Pero es posible atender a las circunstancias políticas, económicas, sociales y culturales que llevaron a que los ensayos de pactos sociales aludidos no hayan funcionado en este especial país para evitarlas.

6.- El actual bloque de constitucionalidad federal, conformado por la Constitución Nacional y tratados sobre derechos humanos incorporados con nivel constitucional en 1994, donde se consagra el principio de progresividad ${ }^{57}$, impide el dictado de normas provenientes de acuerdos intersectoriales que perjudiquen los derechos de los trabajadores.

7.- Argentina está ligada por la Declaración de la OIT sobre la justicia social para una globalización equitativa de 2008, que "expresa la visión contemporánea del mandato de la OIT en la era de la globalización. Uno de sus objetivos estratégicos para la concreción del Programa de Trabajo Decente es la promoción del diálogo social.

A pesar de los fracasos reiterados anteriores, ése es el camino.

57 CSJN, 11/8/2004, "Aquino, Isacio c/ Cargo Servicios Industriales S.A.": "Un principio arquitectónico del Derecho Internacional de los Derechos Humanos en general, y del PIDESC en particular es el de progresividad, "según el cual, todo Estado Parte se "compromete a adoptar medidas [...] para lograr progresivamente [...] la plena efectividad de los derechos aquí reconocidos" (art. 2.1)..."Existe una "fuerte presunción" contraria a que dichas medidas regresivas sean compatibles con el tratado, sobre todo cuando la orientación del PIDESC no es otra que "la mejora continua de las condiciones de existencia", art. 11.1. "El mentado principio de progresividad, que también enuncia la Convención Americana sobre Derechos Humanos precisamente respecto de los derechos económicos y sociales (art. 26). 
REVISTA DE ESTUDIO DE DERECHO LABORAL Y DERECHO PROCESAL LABORAL 